\title{
Gubernamentalidad, populismo penal y prácticas punitivas en Argentina
}

\section{Resumen:}

El presente artículo abordará las características que asume el punitivismo actual, particularmente en Argentina y la implementación de medidas, estrategias y discursos políticos que canalizan la nueva penalidad neoliberal a partir de una mirada desde el concepto de gubernamentalidad. Esta nueva penalidad tiene condición de posibilidad a través de la nueva oleada de neoliberalismo en la región, que se caracteriza entre otras cosas por el refuerzo de modelos de exclusión social, políticas regresivas y una regresión en materia de derechos humanos y sociales.

Palabras clave: Populismo penal, prácticas punitivas, gubernamentalidad, políticas de seguridad, inseguridad.

\section{Summary:}

This article addresses the characteristics assumed by current punitivism, particularly in Argentina, and the implementation of measures, strategies and political discourses of the new neoliberal penalty from the per-

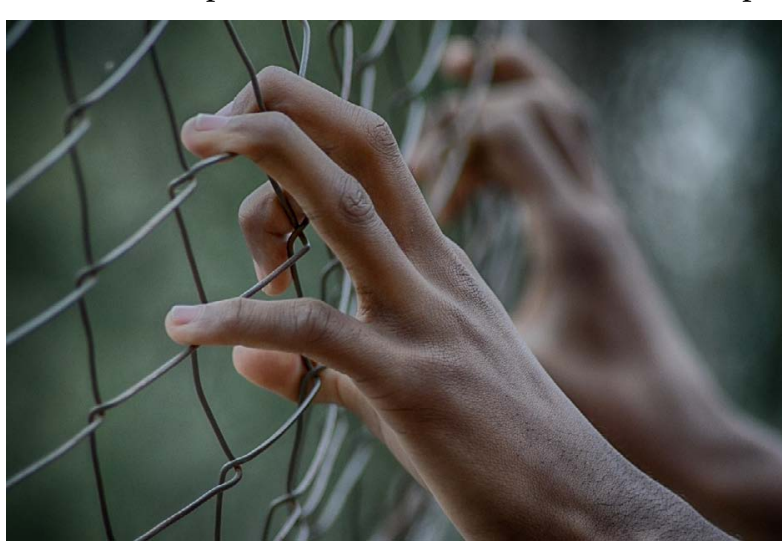
spective of the concept of governmentality. This new penalty has a condition of possibility through the new wave of neoliberalism in the region, which is characterized, among other things, by the reinforcement of models of social exclusion, regressive policies and a regression in terms of human and social rights.

Keywords: Penal populism, punitive practices, governmentality, security policies, insecurity.

Florencia Beltrame: Universidad Nacional de Lanús florenciabeltrame@gmail.com https://orcid.org/00000002-2772-1727 Licenciada en Sociología por la Universidad de Buenos Aires (UBA). Especialista en Estudios Críticos del derecho y Derechos Humanos por el Consejo Latinoamericano de Ciencias Sociales (CLACSO) y Escuela Latinoamericana de Políticas Públicas (ELAP). Maestranda en Ciencias Sociales por la Universidad Nacional General Sarmiento (UNGS) y el Instituto de Desarrollo Económico y Social (IDES). Investigadora del Instituto de Justicia y Derechos Humanos de la Universidad Nacional de Lanús (UNLa). Es Jefa de Trabajos Prácticos en el Seminario de Justicia y Derechos Humanos y docente instructora en la Licenciatura en Justicia y Derechos Humanos de la UNLa. Participa como integrante del Tribunal Internacional Experimental en Derechos Humanos de la UNLa. Recibido, 14/08/20, Publicado 09/10/20 


\section{Introducción}

El fenómeno de la violencia y la criminalidad ha crecido de forma exponencial en los últimos años a lo largo de las distintas regiones del mundo. Dicho fenómeno ha adquirido cada vez una mayor complejidad y, junto a ello, han ido variando las estrategias políticas para su abordaje. En la mayoría de los países de nuestra región, el problema de la inseguridad se instaló en las agendas nacionales como tema prioritario y eje de campañas políticas. Si bien se reconoce, desde los principales organismos de derechos humanos, a la seguridad ciudadana ${ }^{1}$ como la perspectiva deseable que propone un abordaje integral sobrela inseguridad y desde una perspectiva de derechos humanos por sobre los mecanismos tradicionales centrados principalmente en la coerción y uso de la fuerza, lo cierto es que en los últimos ańos asistimos a un recrudecimiento de las políticas de seguridad orientadas a la aplicación de medidas de 'mano dura' o 'tolerancia cero' y un rol central de las herramientas penales para su abordaje.

1En el Informe Seguridad Ciudadana y Derechos Humanos de la Comisión Interamericana de Derechos Humanos (CIDH) se considera a la seguridad ciudadana como [... una de las dimensiones de la seguridad humana -y por lo tanto del desarrollo humano- e involucra la interrelación de múltiples actores, condiciones y factores entre lo cuales se cuentan la historia y la estructura del Estado y la sociedad; las políticas y programas de los gobiernos; la vigencia de lo derechos económicos, sociales, culturales; y el escenario regional e internacional. La seguridad ciudadana se ve amenazada cuando el Estado no cumple con su función de brindar protección ante el crimen y la violencia social, lo cual interrumpe la relación básica entre gobernantes y gobernados" (CIDH 2019: XIX).

Revista Perspectivas Metodológicas | Universidad Nacional de Lanús | ISSN 2618-4125

2 Como daremos cuenta a lo largo del trabajo utilizaremos diversas categorías para da cuenta del proceso socio-histórico que tiende a una exacerbación del uso de herramientas penales y/o un incremento del punitivismo para el tratamiento de la inseguridad. Para ello, hablaremos de populismo penal o punitivo como el proceso social que enmarca el despliegue de dichas estrategias penales y a utilización de aquello que denominamo como prácticas punitivas.

De esta manera, en el presente trabajo abordaremos brevemente las características del punitivismo actual o populismo penal, particularmente en Argentina ${ }^{3}$ y la implementación de algunas de las medidas, estrategias y discursos políticos que canalizan la nueva penalidad posneoliberal (Sozzo, 2016). Esta nueva penalidad tiene condición de posibilidad a través de la nueva oleada de neoliberalismo en la región, que se caracteriza, entre otras cosas, por el refuerzo de modelos de exclusión social, políticas regresivas y una regresión en materia de derechos humanos y sociales.

A partir de las consideraciones hechas anteriormente, el populismo penal debe analizarse a la luz de determinados procesos sociales e históricos que representan las condiciones de posibilidad para su emergencia como estrategia política, y entendido a partir de un complejo entramado de discursos, prácticas y racionalidades gubernamentales.

\section{Sobre la gubernamentalidad: Las prácticas punitivas como dimensión de análisis}

El concepto de gubernamentalidad propuesto por Foucault se vincula, particularmente, al núcleo propio de las sociedades modernas, el paradigma de la biopolítica y a los procesos de conformación de las subjetividades modernas. La gubernamentalidad en términos del propio autor es definida a partir de tres ideas:

[...] el conjunto constituido por las instituciones, los procedimientos, análisis y

\section{tituciones, los procedimientos, análisis y}

3 Recientemente en Argentina se realizaron elecciones nacionales, que implicaron un recambio de las autoridades nacionales y provinciales. El presente trabajo se limitará para el análisis central al periodo tempora comprendido durante los últimos años hasta 2019. Vale aclarar que, desde el cambio de gestión nacional, ya se realizaron modifaciones en las políticas de seguridad; pero que, a los tiempos de este trabajo y dado e carácter reciente de dicho proceso, no es posible incorporar en este escrito. reflexiones, los cálculos y las tácticas que permiten ejercer esa forma bien específica, aunque muy compleja, de poder que tien por blanco principal la población por por blanco pincipar por forma mayor de sabe la economía política y por instrumento técnico esencial lo dispositivos de seguridad. Segundo, po 'gubernamentalidad' entiendo la tendencia, la línea de fuerza que, en todo Occidente, no dejó de conducir, y desde hace mucho, hacia la preeminencia del tipo de poder que podemos llamar 'gobierno' sobre que pode 'gobierno' sobre todos los demás. soberanía, disciplina, que indujo, por un lado, el desarrollo de toda una serie de aparatos específicos de gobierno, [y por otro] el desarrollo de tod una serie de saberes. Por último, creo que habría que entender la 'gubernamentalidad' como el proceso o, mejor, el resultado de proceso en virtud del cual el Estado de justici de la Edad Media converido Estado a ministativo en Estado administrativo durante los siglo XV y XVI, se 'gubernamentalizó' poco a poco. (Foucault, 2006, p. 136)

Dentro de este concepto de gubernamentalidad, proponemos distinguir tre dimensiones analíticas: el de las racionalidades políticas, es decir, de la manera en que las prácticas se toman como objeto de reflexión y pensamiento; el de las tecnologías de gobierno, referido a la articulación de las múltiples prácticas de gobierno y dispositivos de poder; y el de las tácticas y estrategias en las que se inscriben estas tecnologías y que remiten a las relaciones de poder en tanto relaciones entre libertades y sus cercenamientos. Las tres dimensiones mencionadas son tres maneras de considerar una multiplicidad de prácticas concretas, entre ellas, las prácticas punitivas.

Tácticasy Estrategias: Esto implica pensar las prácticas punitivas a partir de su uso táctico, es decir, su reapropiación para dominar la producción de unos efectos sobre las conductas de los otros. A partir de esa mirada, es también posible re-situar las tensiones existentes en la actualidad respecto a las 
formas de entender y abordar la inseguridad por parte de las políticas de Estado. El uso de prácticas punitivas responde a una manera específica de abordar el tema de la inseguridad, contiene una serie de saberes que le dan sustento y legitimidad e impactan como método de disciplinamiento social

Tecnologías de gobierno: La noción de tecnología de gobierno remite a las prácticas en tanto instrumentos técnicos del ejercicio del poder, mecanismos prácticos $\mathrm{y}$ reales, locales que instrumentalizan el ejercicio del poder, produciendo con su puesta en funcionamiento unos determinados efectos (Foucault, 2006). Pero, sobre todo, cuando se analizan las prácticas en tanto tecnologías de gobierno, lo importante no son sólo las determinaciones y prescripciones institucionales sino las relaciones de fuerza que atraviesan y ponen en funcionamiento los mecanismos que constituyen esas prácticas, que cristalizan en esas instituciones. El uso de la prisión preventiva, ciertos usos de la fuerza letal policial, y la presentación de las noticias en los medios de comunicación en relación al problema son, desde esta mirada, tecnologías de gobierno con efectos muy precisos y condiciones de posibilidad que remiten al contexto en el que emergen y las hace peculiares respecto a otros contextos.

Racionalidades políticas: La racionalidad política como dimensión de la gubernamentalidad remite a la relación saber-poder (Raffin, 2018). El problema de la racionalidad es abordado por Foucault en numerosas publicaciones. Esta noción es trabajada en relación con la crítica de la modernidad y de su sujeto. Foucault propone que, en lugar de la razón única, universal y en permanente desarrollo, lo que se despliegan son racionalidades múltiples y locales que son inmanentes a las prácticas, y las organizan.

Cuando Foucault trabaja la cuestión de la racionalidad política, esta especificación implica algunos desplazamientos y ajustes de sentido. En Nacimiento de la Biopolítica de Foucault (2009) ya no aparece tanto la noción de 'dispositivo', sino que, en cambio, el autor utiliza con frecuencia el concepto de 'racionalidad política'. Esto se podría deber a que el filósofo francés quiere introducir el pensamiento como actividad y práctica constitutiva del ejercicio del poder. La reflexión y el pensamiento como práctica es una práctica de gobierno cuyo principio organizador puede ser nombrado como racionalidad política. En tanto tal, la racionalidad política no constituye simplemente estilos de razonamiento o argumentación, sino que refiere a la materialidad de una práctica, la de pensar las relaciones de gobierno; y en las relaciones de gobierno, "la instancia de la reflexión en la práctica de gobierno y sobre la práctica de gobierno, la racionalización de la práctica gubernamental como 'arte de gobierno'” (Foucault, 2009, p. 15). En relación al problema de la inseguridad y sus efectos sobre las prácticas punitivas, el análisis de las racionalidades políticas adquiere suma importancia: qué se dice, cómo y desde dónde dejan de ser elementos complementarios para constituirse en elementos centrales del análisis.

Desde esta perspectiva, es posible indagar en transformaciones y continuidade respecto de las tecnologías de gobierno que implican una articulación de formas de saber de poder y de subjetivación, sin partir del concepto de Estado como estructurante de análisis, pero para retomarlo luego como 'efecto de conjunto' respecto de esta multiplicidad de prácticas y relaciones, y de la manera en que se piensa en y desde, por y para, estas mismas relaciones, en particular las que tienen que ver con el delito.

\section{Ascenso del populismo penal}

Actualmente, en un contexto donde el fenómeno de la violencia (Anitúa, 2015) ha crecido de forma exponencial en distintos países de la región de América Latina, la estrategia desde el poder político para su regulación o control se ha inclinado nuevamente por una respuesta punitiva y un discurso de mano dura.

El fenómeno del miedo y la inseguridad asociados al delito y la violencia urbana se ubicaron como estructurante mismo en la configuración política de las sociedades contemporáneas. Del mismo modo, las funciones del Estado en materia penal y de seguridad se vieron reformuladas, presentando nuevos modos de intervención, y articulándose de un modo diferente con el derecho penal y con las políticas criminales. Las transformaciones en las formas de pensar y de gobernar la inseguridad deben ser pensadas a partir de las transformaciones que produjo la nueva avanzada neoliberal en tanto son parte del mismo proceso. Las formas en que se piensa el delito y se lo aborda no son ajenas a los modos en que el neoliberalismo define y construye un tipo de Estado, de relación económica, política y cultural, sino que todas esas series forman parte de un mismo proceso. Neoliberalismo entendido, según propone Foucault, como un arte de gobierno y una nueva forma de racionalidad política (Ambrosini, 2017).

Cabe aclarar que este fenómeno, en muchos casos, no responde necesariamente a un incremento real de las tasas de delito, sino que muchas veces se encuentra vinculado con una preocupación que atraviesa la ciudadanía y que es retomada por actores políticos como eje de campaña. Más aún, como señala Dammert (2009), podemos afirmar que:

[...] el populismo penal surge como una reacción política a las ansiedades propias de la modernidad tardía, que se reflejan particularmente en el incremento de la criminalidad y la percepción de inseguridad. minalidad y la percepción de inseguridad.
Las políticas criminales, al igual que las de seguridad pública, se configuran a partir de os intereses en juego de diversos grupos: los actores políticos, la opinión pública y los medios de comunicación, los cualesen on tir de crisis ante la necesidad de obtener resultados prontamente. (Dammert, 2009, p. 21)

En la misma línea, Garland (2005) caracteriza este proceso a partir de un cambio en la modalidad penal que rompe con el llamado welfarismo penal, ${ }^{4}$ característico del modelo de Estado de Bienestar. En este escenario es que Garland da cuenta de que dichas transformaciones en el campo del delito son consecuencia de los procesos y cambios que se desarrollaron con la modernidad tardía y forjados en torno a nuevas condiciones culturales y sociales y en el marco de la emergencia de nuevas articulaciones y estructuras sociales, nuevas relaciones sociales y una nueva cultura política:

[...] el carácter arriesgado e inseguro de las relaciones sociales y económica actuales es la superficie social que da origen tanto a nuestra nueva preocupación enfática y generalizada por el control como a la velocidad y afán con que segregamos, fortificamos y excluimos. Es esta circunstancia de fondo la que aliment nuestros intentos obsesivos de mantene bajo vigilancia a individuos sospechosos,

4 Como identifica Garland (2005), el welfarismo penal tiene sus raíces en la década $\mathrm{d}$ 1890 y su desarrollo en las décadas del 50 y 60. Hacia 1970, este paradigma constituy el marco consolidado de las políticas públicas en Gran Bretaña y Estados Unidos. E welfarismo penal como paradigma proponía un ideal de rehabilitación en lugar del castigo ante la infracción de la ley. A grandes rasgos, los principios que guiaban las medida diseñadas bajo aquel paradigma suponían que la reducción del delito estaría determinada por una reforma social y un crecimiento económico generado por el Estado en tanto garante de la seguridad y responsable de la reforma y el bienestar de aquellos que debían rehabilitarse (Garland, 2005). 
de aislar poblaciones peligrosas e imponer controles situacionales en escenarios que, de otro modo, serian abiertos y fluidos. (Garland, 2005, pp. 314-315)

En línea con lo expuesto, en términos concretos se da un impacto del populismo penal en el campo propiamente penal y las políticas criminales, a través por ejemplo de reformas de las legislaciones tendientes a una mayor severidad penal y debates como la baja de edad de imputabilidad para delitos menores, entre otros. En esta misma dirección, Sozzo (2012) plantea entonces que, entre otras cuestiones, el populismo pena en América Latina se visualiza a través de "el incremento de la punitividad, la búsqueda deliberada en el aumento de la pena y el rol del político profesional, como alguien que busca construir consenso y legitimidad utilizando el incremento de la punitividad, como una moneda de cambio en el mercado político" (Sozzo, 2012, p. 119).

Asimismo, ubicada la percepción de inseguridad por parte de la sociedad civil en determinados tipos de delitos (principalmente los delitos contra las personas y la propiedad), las apelaciones de mayor punitividad se dirigen principalmente a esos tipos de delitos provocados por delincuentes, que mayormente son identificados como jóvenes varones de barrios marginales. Aquello que podríamos denominar siguiendo a Garland (2005) como la 'criminología del otro'. Ese 'otro' es aquel que se presenta como peligroso y a quien se debe transformar. Esta criminología aboga por medidas altamente punitivas y presenta a Estado como fuente del control y responsable de aplicar dichas medidas. En este marco, el delito es re-dramatizado y abordado a través de una retórica de defensa social y guerr contra el mismo. Los delincuentes son individuos intrínsecamente desviados y perversos, constituyen aquellos 'otros peligrosos' que no interesa que sean reformados o la condición social en la que se encuentran.

Revista Perspectivas Metodológicas | Universidad Nacional de Lanús | ISSN 2618-4125| cos de una campaña contra la inseguridad y propuestas de políticas de 'mano dura' para enfrentar el problema. De esta manera, en e marco de una profundización de políticas de corte neoliberal, es que podemos advertir y caracterizar al nuevo giro punitivista, al que Sozzo denomina 'penalidad neoliberal'. Esta nueva oleada punitivista acompañada por los discursos demagógicos que canalizan a través de un uso político el incremento de demandas de la sociedad civil por mayor seguridad logra expandirse como modelo legítimo de interpelación política.

En Argentina esta penalidad neoliberal se expresa a través de distintas medidas, estrategias, tácticas y discursos políticos implementados para afrontar al problema de la inseguridad y que, a su vez, se enmarcan en una doctrina especifica de seguridad. Veremos entonces algunas medidas, tácticas y estrategias y cómo éstas son acompañadas por los discursos políticos y mediáticos para su legitimación. Algunas de ellas consisten en un mayor margen de acción de las policías que agravan los procesos de criminalización de las clases más bajas, participación de fuerzas armadas en tareas de seguridad interior, restricciones de garantías en el proceso penal, aumento de las tasas de encarcelamiento, entre otras.

En líneas generales, compartiendo el diagnóstico del Centro de Estudios, Legales y Sociales en sus últimos Informes Anuales 2017 y 2019, sostenemos también que "aunque se trata de procesos de transición abiertos, en conjunto el cambio de administraciones tiene una tendencia a profundiza el abordaje punitivo, a retroceder en las políticas orientadas a reducir la violencia social e institucional y a garantizar derechos" (CELS, 2017, pp. 83-84). En este marco es que la noción de seguridad adquiere nuevas significaciones que se alejan, en contraposición a la retórica del periodo anterior, de la seguridad ciudadana y comienzan a vincu- larse más fuertemente con la idea de lucha contra el narcotráfico, la identificación de enemigos internos que deben ser combatidos por las Fuerzas Armadas y al delito como una amenaza a los valores de soberanía y seguridad nacional (CELS, 2017). La noción de enemigo interno recaerá en la profundización del estereotipo de los jóvenes varones de barrios populares como los causantes de la inseguridad social. En definitiva, la guerra contra el narcotráfico culmina en una 'guerra contra los pobres' que ha implicado "[...] la detención a manos de las fuerzas de seguridad, de miles de personas sobre todo en barrios pobres y en las fronteras, y en el posterior encarcelamiento de un número creciente de ellas" (CELS, 2019, p. 123).

A partir de la retórica de la lucha contra el narcotráfico se realizan intervenciones en barrios, se incrementa la presencia policial y se legitiman los controles arbitrarios policiales y poblacionales. El Plan Barrios Seguros fue una expresión de dichas intervenciones. La noción de 'lucha' legitima las intervenciones 5 y prácticas punitivas violentas, pone en un mismo eslabón de responsabilidad a consumidores, pequeños traficantes y grandes vendedores, y se alinea con la política de las

5 A partir del 2016 se ha implementado el programa 'Barrios Seguros'. El mismo comenzó en el Barrio 31 y 31 bis de la Ciudad Autónoma de Buenos Aires, continuando por Alto Verde en la provincia de Santa Fe Carlos Gardel y Borges en provincia de Buenos Aires y 1.11.14 en la Ciudad Autónom de Bueno Aires; siendo los mismos los más emblemáticos. 'Barrios Seguros' es llevad adelante, coordinado y supervisado por la Subsecretaría de Prevención del Delito y la Violencia dependiente de la Secretaría de Seguridad bajo la órbita del Ministerio de Seguridad. El objetivo fundamental es reduci a presencia de la criminalidad organizada, el narcotráfico, el delito y la violencia en aquelos barrios identificados como prioritarios por sus altos índices de conflictividad social, en articulación con el gobierno nacional, lo gobiernos locales y otros poderes del Estado. 
'nuevas amenazas' siguiendo las directrices de seguridad de la política de Estados Unidos. En base a esta idea, en enero de 2016 a través del decreto 228/2016 se declaró la emergencia de seguridad pública "con el objeto de revertir la situación de peligro colectivo creada por el delito complejo y el crimen organizado" ${ }^{6}$. Este decreto, que fue ampliamente cuestionado por organizaciones sociales, de derechos humanos y diversos actores del espectro político, habilita la intervención directa y letal de las fuerzas militares en temas de seguridad interior (CELS, 2017, 2019). En este marco es que también se pone énfasis en el control de población, a través de la implementación de 'Operativos de Control Poblacional Conjunto' realizados por las cuatro fuerzas federales, que habilitó las detenciones arbitrarias que recurren a la conocida 'portación de rostro' y profundizan la estigmatización social hacia jóvenes pobres. A partir de la retórica de lucha contra el narcotráfico, el despliegue de operativos que han sido denunciados por sus prácticas violentas son legitimados y presentados como la respuesta más efectiva en la lucha contra el narcotráfico.

Varias de estas nuevas amenazas -a través de las distintas políticas- parecen canalizarse, como bien dijimos, en las figuras de los jóvenes de barrios vulnerables, pero también en la figura de los migrantes (en este sentido ver el decreto 70/2017, que reforma la Ley de Migraciones) y los pueblos indígenas (se multiplicaron los operativos ilegales y violentos a cargo de Gendarmería Naciona en protestas de comunidades indígenas).

En línea con el decreto 228/2016, se firmó posteriormente el decreto 668/2016, que modifica las funciones de las Fuerzas Armadas y habilita, por un lado, el avance hacia la participación de las mismas en la

6 Ver en: https://www.lanacion.com. ar/1864382-oficializan-la-declaracion-de-emergencia-en-seguridad.

Revista Perspectivas Metodológicas | Universidad Nacional de Lanús | ISSN 2618-4125|
Servicio Penitenciario Federal de 12.235 plazas. Este panorama relata una aguda crisis del sistema carcelario argentino. Pese a haberse declarado la emergencia en materia penitenciaria (Resolución 184/2019), no se han tomado medidas ni políticas adecuadas para abordar la problemática ni se han mostrado indicios sobre un cambio en el abordaje y trayectoria punitivista.

Como bien explicamos, una de las medidas que frecuentemente pregonan las políticas de mano dura y tolerancia cero es la construcción de más cárceles y el incremento de la población carcelaria como medida que regule la inseguridad. En nuestro país, la tendencia del incremento sostenido de la tasa de encarcelamiento no registra índices exitosos en relación con una disminución o control de la problemática, sino que más bien -como advierten los Informes de la PPN"[...] marca una situación preocupante para la realidad carcelaria argentina, ya que no hay indicios de que esta propensión creciente se detenga o revierta, ni de que existan políticas públicas ni judiciales orientadas a revertir este proceso" (Informe 2017, p. 34). En definitiva, las personas que van presas son las más vulnerables a ser criminalizadas, así como son las más vulnerables y excluidas del sistema social y no existen políticas integrales de reinserción social.

Ahora bien, a nivel discursivo vemos cómo las estrategias que se despliegan sobre los temas de seguridad fortalecen la legitimación de medidas punitivas (discursos punitivos). Así, por ejemplo, vemos que predomina una retórica que incentiva a la alarma social por el incremento del delito, pero que también cuestiona el 'no tan duro' sistema de castigos de los delincuentes comunes; a partir de lo cual también se ha instalado y se puso en agenda el debate de una reforma del código penal que contenga penas más duras.

Revista Perspectivas Metodológicas | Universidad Nacional de Lanús | ISSN 2618-4125
Otro tema que se ha instalado en el debate público en los últimos años es la baja de edad de punibilidad que incluso fue una propuesta de varios miembros del gobierno nacional -que ha cambiado recientementeutilizando como argumento la asociación directa entre el aumento de las tasas de delitos comunes y la participación en los mismos de personas de cada vez más baja edad. Esta iniciativa del Poder Ejecutivo se fundamentó en casos que conmocionan a las audiencias a través de la repetición de imágenes y de analistas mediáticos que apelan a la emotividad de las víctimas o de las potenciales víctimas de la inseguridad con repertorios morales estigmatizantes, desoyendo las propias estadísticas oficiales que desmienten la relación entre la participación de adolescentes de 14 ó 15 años en el aumento de ese tipo de delitos.

Otra expresión en el plano discursivo del ascenso del populismo penal en el contexto nacional ha intentado presentar al garantismo penal como una opción 'menos justa' e ineficaz para tratar el tema de la inseguridad. Discursivamente el garantismo es caracterizado como un modelo que no supo dar respuestas a la creciente inseguridad. Como expresión de ello, cabe mencionar el caso 'Chocobar', que tuvo alta resonancia

8 El 8 de diciembre de 2017 en el barrio de La Boca dos delincuentes asaltaron a un turista, Frank Joseph Wolek, de 60 años, y uno de ellos le dio diez puñaladas en el intento de robo. Tras ello, los delincuentes huyeron del lugar. Uno de ellos fue interceptado por transeúntes y el otro, que también intentab escapar, recibió disparos de Luis Chocobar, integrante de la policía local que había visto la secuencia y se encontraba de civil. Chocobar sostuvo que el ladrón intentó atacarlo por ello tuvo que dispararle. Cinco días después, Pablo Kukok de 18 anos murió debido a los disparos. El 1 de febrero de 2018, e presidente Mauricio Macri recibió en la Casa Rosada al agente de la policía local para feicitarlo por su accionar y le expresó: "Estoy orgulloso de que haya un policía como vos, 
pública porque refleja un exceso en el uso de la fuerza que, sin embargo, fue presentado como acción 'heroica' por parte de las autoridades nacionales. ${ }^{9}$ Posteriormente, se comenzó a debatir el 'efecto Chocobar' debido a que se sucedieron hechos similares de muertes por 'gatillo fácil' por parte de las fuerzas de seguridad ante hechos de delitos de hurto cometidos por jóvenes varones principalmente de barrios pobres. Los medios de comunicación refuerzan esta idea de un estado de inseguridad que hay que controlar contribuyendo a que gran parte de la sociedad civil esté de acuerdo y apoye

las políticas de mano dura.

\section{Reflexiones finales}

Desde hace años las sociedades latinoamericanas atraviesan procesos caracterizados como 'emergencias' respecto a la seguridad y a la violencia. Los modos en que han sido abordadas estas problemáticas han ido variando, pero siempre prevaleció la utilización del sistema penal como respuesta a problema. En periodos como el reciente, de una prevalencia del populismo punitivo, se da una utilización exacerbada de la herramienta penal sobre aquellos sujetos que han sido marcados como los causantes de la inseguridad. El concepto de peligrosidad

al servicio de los ciudadanos". A su vez, la ministra de seguridad, Patricia Bullrich consideró: "Vamos a cuidar a quienes nos cuidan, y Chocobar actuo en cumplimiento de su deber policial". El hecho es que comenzó a circular el vídeo del acontecimiento donde se puede ver que Pablo Kukok no amenazó al agente Luis Chocobar ni a ninguna otra persona mientras trataba de escapar. Sólo corrio hasta recibir varios disparos por la espalda y caer al piso, desde donde parece levantar las manos para que ya no le disparen.

9 Luego del debate público y la denuncia po el accionar indebido del policía, el caso llegó a la justicia. Luis Chocobar fue procesado y embargado por $\$ 400 \mathrm{mil}$ cional que es funcional a una determinada estructura de poder. Las características que presentan las cárceles hoy en día, como la superpoblación, el hacinamiento, la prevalencia de tratos inhumanos, degradantes y de tortura, las malas condiciones materiales (acceso a elementos de higiene), falta de acceso a educación y salud, entre otras son características estructurales y no coyunturales del sistema carcelario. Todas estas condiciones, lejos de abogar por una rehabilitación o reinserción de las personas privadas de libertad, terminan contribuyendo a una reproducción de la delincuencia.

Actualmente, las tensiones que present el Estado de Derecho respecto al tratamiento del tema de la seguridad dejan un terreno fértil que facilita y legitima medidas punitivas que avanzan contra el aseguramiento y garantía de los derechos humanos y terminan por debilitar al propio sistema democrático. El papel de los derechos humanos resulta fundamental si lo pensamos como un límite a la expansión punitiva. Tal como expresa Baratta (2004), resulta necesario adoptar esta perspectiva de cara a los contextos actuales y desde una mirada que contenga e incorpore el fenómeno de la violencia como estructurante de las sociedades contemporáneas y como componente del sistema penal.

\section{Bibliografía}

-Anitúa, G. (2015). “Diez años después”. [Prólogo a la nueva edición de Historias de lospensamientos criminológicos]. Buenos Aires: Didot.

- Baratta, A. (2004). Criminología y sistema penal. Montevideo-Buenos Aires: Editorial B de F.

- CELS (2017). Informe Anual 2017. Buenos Aires: Siglo XXI-CELS.

CELS (2019). Informe Anual 2019. Buenos Aires: Siglo XXI-CELS.
- Dammert, L. y F. Salazar (2009). ¿ Duros con el delito? Populismo e Inseguridad en América Latina. Mexico: FLACSO.

- Foucault, M. (2005). Vigilar y castigar. Nacimiento de la Prisión. México DF: Siglo XXI.

(2006). Seguridad, territorio y población. Buenos Aires: FCE.

(2009). Nacimiento de la biopolitica. Buenos Aires: AKAL.

- Garland, D. (2005). La cultura del control. Madrid: Gedisa.

- Kessler, G. (2009). El sentimiento de inseguridad: Sociología del temor al delito. Buenos Aires: Siglo XXI.

- Raffin, M. (2008). El pensamiento de Gilles Deleuze y Michel Foucault en cuestión: Las ideas en torno del poder, el sujeto y la verdad. Revista Lecciones y Ensayos, 85 $17-44$

(2018). La noción de política en la filosofía de Michel Foucault. Revista Hermenéutica Intercultural, 29.

- Rivera Beiras, I. [coord.] (2005). La politica criminal y sistema penal. Viejas nuevas racionalidades punitivas. Barcelona: Antrophofos.

- Sozzo, M. (2012). ¿Qué es el populismo penal? Revista Latinoamericana de Seguridad Ciudadana, pp. 117-122.

(2016). Postneroliberalismo penalidad en América del Sur. Buenos Aires: CLACSO.

Revista Perspectivas Metodológicas | Universidad Nacional de Lanús | ISSN 2618-4125 